\title{
Attribution of success as a function of locus of control and objective self-awareness
}

\author{
CHARLES S. CARVER \\ University of Miami, Coral Gables, Florida 35124
}

\begin{abstract}
Several studies have failed to validate Rotter's IE control of reinforcement construct through the attribution of ambiguously caused successes by Internals and Externals. The present study was another attempt to validate the construct using a new locus of control measure. Additionally, two predictions derived from self-awareness theory were tested. Attributions were made as estimated influences of four causal categories, and as a global partition of responsibility into internal vs. external factors. Internals and Externals differed only on attribution to chance. On the global measure, self-awareness produced more internality among Externals and an opposite tendency among Internals. Two possible interpretations of this result were discussed.
\end{abstract}

Internal-External locus of control (Rotter, 1966) refers to persons' generalized tendencies to perceive reinforcements as contingent on their behaviors and abilities (Internal) or as dependent on outside forces such as luck, fate, or powerful others (External). These expectancies are held to be important in influencing the course of learning; i.e., when rewarded. Internals perceive their behavior as instrumental but Externals do not.

Attempts have been made to validate these generalized expectancies through studies of causal attribution of actually experienced outcomes. Results have varied, Internals and Externals displaying no differences in their attributional tendencies (Dies, 1968; Fitch, 1969; Lackey, 1968), or differing only when attributing failure outcomes (Davis \& Davis. 1972; Phares, Wilson, \& Klyver, 1971). It is somewhat perplexing, as control over reinforcement was the central notion in Rotter's theorizing, that in none of the above studies has a difference been demonstrated between Internals and Externals in the attribution of successes. One purpose of the present study was to attempt to demonstrate such a difference.

Secondly, to determine what effect, if any, the mode of attribution has on the attribution itself, independent-category attributions were made, based on Heider's (1958) four causal factors, followed by a global one-scale rating, dividing causality into proportions of internal vs. external influences.

A third purpose of the study was to test two attributional predictions derived from a recent theory of objective self-awareness (Duval \& Wicklund, 1972). One is that self-awareness (OSA) may increase the internality of causal attributions among all subjects by making the individual more aware of himself

Neil Schneiderman sponsors this paper and takes full editorial responsibility for its content. as a causal agent. This hypothesis was supported in several experiments (Duval \& Wicklund, 1972, 1973) in which unselected subjects made one-scale attributions of the causes of hypothetical outcomes. However, more complex predictions can be derived from the theory, which also states that self-focused attention causes a person to behave in closer conformity to whatever standard is salient. If personal standards are salient, increased OSA should intensify pre-existing individual differences. As different persons conform more closely to their own norms, their behaviors will diverge from each other (Carver, 1975). It seems possible that self-awareness similarly might intensify subjects' control orientations, causing Internals to attribute causality more internally, Externals more externally, than low-OSA controls. Self-awareness theory thus leads to two possible predictions regarding the effects of increased OSA on attributions: Attributions may become more internal among all subjects, or pre-existing differences in attributional tendencies may be increased. To test these possibilities, self-awareness was heightened by the presence of a mirror for half the Internals and half the Externals while they made their attributions.

\section{METHOD}

\section{Pretest}

Locus of control in experimental subjects typically is assessed by Rotter's (1966) IE scale. Although the scale has been widely used, it has been criticized on several grounds: it does not allow for possible differences between beliefs about one's own control and the control held by people in general (Gurin, Gurin, Lao, \& Beattie, 1969; Lao, 1970), between control over events which impinge directly on one's life and those which exist as remote abstractions, e.g., international politics (Mirels, 1970), or between orientations toward success outcomes and failure outcomes (Davis \& Davis. 1972; Phares et al., 1971). In line with these criticisms. a new locus of control measure was devised for the present study. Each item of this Control Attribution Questionnaire (CAQ) contains one statement, written in first person, about the causality of some event (stated internally half the time. externally half the time). ${ }^{1}$ Respondents choose from 
Table 1

Attributions of Causality for a Success Outcome: Four Independent Categories and a Global Assessment of Percentage Internal Factors

\begin{tabular}{|c|c|c|c|c|c|}
\hline & Ability* & Effort * & Chance* & $\begin{array}{c}\text { Task } \\
\text { Diffi- } \\
\text { culty * }\end{array}$ & $\begin{array}{c}\text { Global } \\
\text { Division }\end{array}$ \\
\hline \multicolumn{6}{|l|}{ Internal } \\
\hline No Mirror $† \dagger$ & 7.11 & 7.56 & 2.98 & 6.33 & 74.4 \\
\hline Mirrort & 6.30 & 7.10 & 2.60 & 5.40 & 66.0 \\
\hline \multicolumn{6}{|l|}{ External } \\
\hline No Mirror $\dagger$ & 6.70 & 7.10 & 4.50 & 5.50 & 52.0 \\
\hline Mirror† & 7.10 & 7.40 & 5.20 & 6.50 & 68.0 \\
\hline
\end{tabular}

five answers, from strong agreement to strong disagreement with the statement. As the CAQ was intended for student populations. each item concerns a situation of personal relevance to college students. The items are divided into an 11 -item positive outcome subscale composed of attributional statements about successful or "reinforcing" outcomes (e.g.. "Good grades are directly related to the amount of studying I do."), and an 11-item negative outcome subscale composed of statements about outcomes that are unfavorable or "punishing" (e.g.. "I have very little control over the misfortunes that befall me."). Responses are summed to yield two scores representing control attitudes for good and bad events. As with the IE scale, low scores represent internal attitudes. Each subscale yields a relatively normal distribution. Retest reliability correlations from two independent samples indicate moderate stability for the subscales $(r=.53$ for each subscale after 6 weeks. $\mathrm{n}=87: \mathrm{s}=.54 . .67$ for the subscales after 3 months, $\mathrm{n}=41$ ). The CAQ subscales correlate moderately with the IE ( $\mathrm{rs}=.60 . .46$. $\mathrm{n}=165$ ), indicating some relationship between the measures, but not so high as to indicate a total overlap between them. The positive and negative subscales correlated from .29 to .44 in these three samples, suggesting that somewhat separate attitudes do exist for success and failure.

In the belief that this questionnaire more accurately measured control orientations for immediate, personally relevant outcomes than did the IE. the CAQ was utilized as the locus of control premeasure.

\section{Subjects}

College students completed the CAQ early in the semester. Two subpopulations were established on the basis of the pretest. Internals were $1 \mathrm{SD}$ or more below each subscale mean; Externals were $1 \mathrm{SD}$ or more above the means. Thus the subjects in the experiment represented extremes in their self-reported beliefs about control. Twenty Externals and 19 Internals subsequently completed the experiment. ${ }^{2}$

\section{Procedure}

The experiment was an individual session, occurring several months after pretesting. The experimenter described the study as a preliminary evaluation of items being considered for use in a new intelligence test. Subjects were to work on a problem set and then make ratings about the problems on a questionnaire.

Problems and success manipulation. Subjects were provided a pen and four different geometric patterns (after Feather, 1963), and were instructed to trace each pattern according to two rules: (1) Once begun, the tracing had to be made in one continuous line. (2) Each line of the drawing had to be covered once and only once. The experimenter indicated that the task was somewhat difficult: given a six-attempt limitation, previous subjects had averaged two correct out of the four problems in the set. This was to ensure that subjects would perceive their performances as successes. In actuality all items, though appearing difficult, were solved easily with a minimum of concentration. The subject was left alone while working on the problems.
Self-awareness. After completing the line problems and returning to the experimenter. the subject was given a questionnaire to complete. The experimenter left the room, ostensibly to prepare for the next subject. In the mirror condition a large mirror rested on the table, facing the subject. In the no mirror condition, it was removed. The experimenter who interacted with the subject did not know the purpose of the mirror.

Dependent measures. The questionnaire contained checks on the success manipulation, and then four ratings of the degree to which (1) "your ability," (2) "your effort," (3) "luck or chance factors," and (4) the "level of task difficulty" had influenced the task outcome. Each rating was made independently, on nine-point scales. The subject then was asked to "try to decide how much of the outcome of your performance was caused by internal determinants (things inside yourself, like abilities and persistence) as opposed to external determinants (things outside yourself, like some aspects of the task, luck, etc.)." There was one scale on which to make this global division, as a percentage of internal vs. external control over the outcome.

\section{RESULTS AND DISCCUSSION}

It was hypothesized that Internals would make greater attributions of causality to their abilities and efforts, but less attribution to chance factors and task difficulty, than would Externals. This hypothesis was supported in only one of the four independent attribution categories (see Table 1). Externals attributed a greater influence to chance factors than did Internals, $F(1,35)=7.65, p<.01$. This difference tended to be greater between mirror groups, $\mathrm{t}=2.45, \mathrm{p}<.02$, than between no mirror groups, $\mathrm{t}=1.48, \mathrm{p}<.15$, though the interaction did not approach significance. No other effects were found in the independent-category analyses.

The global attribution scale was scored as percentage of causality assigned to internal determinants (Table 1). On this measure a significant interaction resulted, such that the pretest groups diverged more in the no mirror than in the mirror condition, $F(1,35)=4.04, p<.05$. The External-No Mirror subjects attributed more externally than did the Internal-No Mirror subjects, $t=2.57, p<.02$, and marginally more externally than did the External-Mirror subjects, $t=1.89, p<.07$. The two Internal groups did not differ from each other, $t<1$, n.s.

These results suggest three conclusions. First, the mode of subjects' attributions did seem to influence the attributions made. The independent-category ratings showed little difference between pretest Internals and Externals, but the global division suggested considerable difference between the pretest groups. This is clearest among subjects in the no mirror groups-subjects most nearly comparable to those of prior research, as their attributions were made with no manipulation of self-awareness. Examining these groups, one sees no difference between Internals and Externals on the influences of the four causal categories (a result consistent with most prior findings), but a large difference when the attribution is made as a global partition of 
responsibility. This argues for caution in the interpretation of data from single-scale measures, and further suggests that the single-scale attribution is not merely the sum of the components enumerated by Heider (1958).

Secondly, the existence, or at least the generality of a locus of control orientation remains in question. The CAQ did little better than the IE has done at predicting attributions of ambiguous successes. To the degree that generalized orientations toward positive reinforcements were supported here, the independent-category attributions suggest that externality may be more heterogeneous than was previously believed (cf. also Hersch \& Scheib, 1967). It appears that at least some externals, rather than lacking beliefs in the influences of their abilities and efforts, may merely temper those beliefs with an awareness of other factors over which they have no control. ${ }^{3}$

Third, the results were equivocal regarding the self-awareness hypotheses. The mirror's presence influenced only the global attributions, causing Externals to attribute more internally and Internals less internally than their respective controls. There are two reasonable interpretations for this: (a) The level of internality demonstrated by both Internal groups (which did not differ significantly from each other) might represent a ceiling on internal attribution. The movement toward internality among Externals under OSA thus would replicate Duval and Wicklund's effects $(1972,1973)$ and partially confirm the hypothesis that OSA causes more internal attributions. (b) Subjects may have attended to a standard of behavior other than that assumed by the experimenter. Subjects believed themselves to be aiding in the evaluation of an intelligence test. Perhaps they inferred that they thus should consider as fully as possible the forces which might influence the outcome. OSA would have caused all subjects to more closely approximate this standard, leading both groups to consider and include in their ratings the influence of causal elements to which they ordinarily do not attend, thus accounting for the convergence of the global ratings under OSA.

\section{REFERENCES}

Carver, C. S. Physical aggression as a function of objective self-awareness and attitudes toward punishment. Journal of Experimental Social Psychology, 1975, 11, 510-519.

Crandall, V. C., Katkovsky, W., \& Crandall, V. J. Children's beliefs in their own control of reinforcements in intellectualacademic achievement situations. Child Development. 1905, 36. 91-109.

Davis, W. L.. \& Davis. D. E. IE control and attribution of responsibility for success and failure. Journal of Personality. 1972. 40, 123-136.

Dies. R. R. IE control, need for social approval, and blame assignment. Unpublished doctoral dissertation. University of Connecticut, 1968.

Duval, S., \& Wicklund, R. A. A theory of objective self-awareness. New York: Academic Press, 1972.

Duval, S., \& Wicklund, R. A. Effects of objective self-awareness on attribution of causality. Journal of Experimental Social Psychology, 1973, 9. 17-31.

Feather, N. T. Persistence at a difficult task, with alternative task of intermediate difficulty. Journal of Abnormal and Social Psychology. 1963, 66. 604-609.

Fiтсн. H. F. The effects of self-esteem. IE control, success-failure, and choice on causal attributions. Unpublished doctoral dissertation. Purdue University. 1969.

Gurin. P.. Gurin, G., Lao, R. C., \& Beattie, M. iE control in the motivational dynamics of Negro youth. Journal of Social Issue's. 1969. 25. 29-53.

HEIDER, F. The psychology of interpersonal relutions. New York: Wilev. 1958.

Hersch. P. D.. \& Scheib, K. E. Reliability and validity of IE control as a personality dimension. Journal of Consulting and Clinical Psychology, 1967, 31, 609-613.

Lackey, R. Attribution of responsibility as a finction of perceived similarity. outcome intensity, and locus of control. Unpublished doctoral dissertation. University of Florida, 1968.

LAO. R. C. IE control and competence and innovative behavior among Negro college students. Journal of Personality and Social Psychology, 1970, 14, 263-270.

Mirels. H. L. Dimensions of IE control. Journal of Consulting and Clinical Psychology, 1970, 34, 226-228.

Phares, E. J., Wilson, K. G.. \& Klyver, N. W. IE control and the attribution of blame under neutral and distractive conditions. Journal of Personality and Social Psychology. 1971. 18. 285-288.

RotTER. J. B. Generalized expectancies for internal versus external control of reinforcement. Psychological Monographs. 1966. 80.

\section{NOTES}

1. All items of the CAQ are available from the author upon request.

2. Each cell consisted of six females and four males except the internal-no mirror cell, which contained six females and three males.

3. That the independent-category attributions of Internals and Externals differed only with respect to chance factors replicated findings of a pilot study in which attributions were made about failures as well as successes.

(Received for publication January 5. 1976.) 